from elsewhere on cheaper paper Dr. Spencer's book is not of this kind; the paper is excellent, the type is large and clear, and the binding and cover seem satisfactory. The majority of the reproductions of illustrations are good. It is not cheap; it costs $£ 10$.

Purchasers should carefully check that the pages are not out of order. This defect is present in at least one copy already sold.

\section{J. GOUGH}

hormones IN bloOd Edited by C. H. Gray and A. L. Bacharach. (Pp. XVIII + 655; illustrated. 140s.) New York and London: Academic Press. 1961.

This volume discusses methods for the assay in blood of the various hormones and the significance of the results. The book is intended for readers qualified in some relevant branch of pure or applied science who need information regarding the analysis of hormones with which they are not familiar; it would prove of little interest to anyone lacking minimal knowledge of chemistry, endocrinology, and laboratory technique. Within these limits the field is well covered.

The endocrine investigations of most hospital laboratories have been confined to analysis of urine for hormones or their metabolites. Analyses of the blood are becoming increasingly important: determinations of protein-bound iodine and of adrenal cortical hormones provide two notable examples. The situation illustrates one of the difficulties of modern medicine. On the one hand, the clinical need for a particular determination makes itself felt, a need which may be made more pressing by the published results of specialized (and perhaps well-known) authors; and, on the other hand, the chemical pathologist (or pathologist advised by his chemical colleagues) is sadly aware of the time and effort which is called for if satisfactory results are to be obtained. Works such as the present help both in the assessment of the analytical difficulties and in the assessment of the probable clinical value of the results of a technique and so make easier the decision whether the analysis should be embarked upon.

The standard of all the contributions is high. The practical interest of different estimations varies considerably, as is to be expected. To workers likely to be confronted with questions relating to determinations of hormones in blood the book can be recommended without reserve.

ARTHUR JORDAN

AN INTRODUCTION TO BLOOD GROUP SEROLOGY, 2nd ed.

By Kathleen E. Boorman and Barbara E. Dodd.

(Pp. 336; 10 plates; 14 text figures. 50s.) London: J. \& A. Churchill. 1961.

This book is now a well-established favourite, particularly with those working in laboratories served by the South London Blood Transfusion Service. The second edition brings blood group serology, apart from 'small print stuff', as nearly up to date as any book can and succeeds pretty well in its attempt to be a technical book with sufficient theoretical content for the ordinary medical or technical blood-bank worker. To decide what to include and what to leave out must be the hardest task for the authors of a book of this nature.

Whether one uses the book or not will be a matter of individual preference. Its whole content speaks of personal experience and any laboratory worker could run a blood-bank with its aid. Techniques are clearly described but not always easy to locate. The method of reference to them as 'technique No. .....,' without a page reference, is unsatisfactory to those not thoroughly familiar with the book. (Appendix IV is a list of techniques, with page references.) On p. 207 several techniques are mentioned without reference numbers. The same criticism applies to the figures. For example, p. 210 refers to fig 5a, but does not say it is on page 42 .

The illustrations are good.

Reading the book, one gets the impression that the authors take for granted that their pet foibles and technical variations are known and accepted, and need no explanation. For many readers this may well be true. But, for example, to read on p. 258 that the Price precipitation reaction (which they call the Price precipitation test) is a two-tube test, using serum neat and diluted one in two, will surprise many and irritate some. No indication is given that this is a modification of the Price precipitation reaction.

The writing itself is open to criticism for its numerous errors in construction, grammar, and punctuation. One need look no further than page 2 for a glaring mistake in number, while punctuation appears somewhat arbitrary and, in places, breathless. There is no uniformity in giving the dates of references. To some readers these points will not matter; to others, the need for editing detracts from the appeal of a book that is altogether too valuable not to deserve continuing success.

Basic neuro-Pathological technique By G. Gasser. (Pp. $\mathrm{x}+77 ; 59$ figures. 20s.) Oxford: Blackwell Scientific Publications. 1962.

The author is the chief technician in the Department of Pathology at the Smethwick Centre for neurosurgery. Anyone who has seen the beautiful preparations shown by Dr. A. L. Woolf at scientific meetings will welcome the appearance of a volume on staining techniques from that department. The object has been to give sufficient information on all the aspects of neuro-pathological technique to enable routine pathologists and histological technicians to tackle the study of central nervous disease systematically and by reliable and well-tried methods.

Post-mortem techniques for removing the skull and brain together, for demonstrating the cervico-medullary junction, and for removing the spinal cord without damage are adequately described. Some of these methods will be rarely used in routine departments, so that a clear description of several different procedures becomes of added value. The necessity for tracing the carotid and vertebral arteries in many cases of cerebrovascular disease is stressed though there will be many dissenters from the view that 'in most cases with ischaemic lesions in the brain the responsible vascular lesion lies outside the cranial cavity', and few pathologists will be prepared, or have the time, to demonstrate the full length of the 